\title{
Fetichismo de la mercancía y emancipación. La recepción de la utopía marxiana en la filosofía materialista de Theodor W. Adorno
}

Fetishism of commodities and emancipation. The reception of Marxian utopia in Theodor W. Adorno's materialistic philosophy

\section{ChaXIRAXI $M^{\mathrm{a}}$ Escuela Cruz}

Universidad de La Laguna

Facultad de Humanidades

Sección de Filosofía

38200 La Laguna, Tenerife (España)

cescuela@ull.edu.es

Abstract: The main goal of this article is to investigate the evolution of Adorno's reading of Marx as a way of understanding the formation of his own materialistic philosophy. Against the orthodox and metaphysical forms of Marxism, Adorno proposes a distinct, undogmatic reading of the materialist theory of history and society.

Keywords: Materialism, Marxism, emancipation, dialectic.
Resumen: Este trabajo se propone revisar los momentos fundamentales en los que se construye la comprensión materialista de la filosofía adorniana, señalando como aspecto clave la recepción del pensamiento de Marx. Frente a las formas ortodoxas y metafísicas del marxismo, Adorno propone la elaboración de una lectura distinta y no dogmática de la teoría materialista de la historia y de lo social capaz de retomar los impulsos críticos y liberadores de la tradición ilustrada.

Palabras clave: Materialismo, marxismo, emancipación, dialéctica. 
a obra de Th. W. Adorno puede ser presentada a la luz de su esfuerzo temprano por comprender el materialismo no como una tesis ontológica, sino como el lugar desde el que es posible abrir una posición distinta para la teoría y para la praxis, una vez fracasado el ideal tradicional de fundamentación basado en los principios de totalidad y de sentido. Sus lecturas de Kierkegaard, Husserl y Benjamin le habían suministrado los instrumentos con los que entender la dialéctica materialista desde un panorama intelectual marcado por la incapacidad de dar respuestas adecuadas (no dogmáticas) a esta nueva situación de crisis de la razón ${ }^{1}$. En estos primeros textos se va forjando un concepto específico de materialismo como interpretación que emerge de las ruinas y los fragmentos en los que se manifiesta la modernidad. "Lógica de la descomposición” y "crítica inmanente" serán sus características principales, pues la insistencia en desvelar la apariencia de pseudonaturalidad y de irreversibilidad de lo que se presenta como eterno constituye una línea maestra en la construcción materialista de su filosofía y, también, el lugar en el que mejor se expresa su dimensión transformadora. Con ello, la crítica materialista no sólo comporta una crítica inmanente al idealismo, sino también el esfuerzo por recuperar los "impulsos originarios" de la tradición ilustrada para alcanzar un cambio de posición para la filosofía. Ello exige una revisión de sus categorías y materiales y, además, una comprensión distinta de la interpretación filosófica

1. Nos referimos a sus ensayos de los años veinte y treinta, que incluyen sus textos de promoción académica, su primer discurso como Privatdozent en la Universidad de Frankfurt y sus artículos sobre la fenomenología de Husserl. Véase Th. W. Adorno, Der Begriff des Unbewußten in der transzendentalen Seelenlebre, en R. TIEDEMANN y G. ADORNO (eds.), Gesammelte Schriften (Suhrkamp, Frankfurt a.M., 1973) vol. 1, 79-322. En adelante, la obra de Adorno será citada con las siglas $A G S$ seguidas del número de tomo y la página correspondiente; Die Transzendenz des Dinglichen und Noematischen in Husserls Phänomenologie, en AGS, vol. 1, 7-77; Die Kierkegaard. Konstruktion des Ästhetischen, en AGS, vol. 2; Zur Husserls Philosophie, en $A G S$, vol. 20.1, 46-118; Husserl and the Problem of Idealism, en AGS vol. 20.1, 119-134; Zur Metakritik der Erkenntsnistheorie. Studien über Husserl und die phänomenologischen Antinomien, en AGS, vol. 5; Die Idee der Naturgeschichte, en AGS vol. 1, 345-365; Die Aktualität der Philosophie, en AGS, vol. 1, 325-344. 
y del propio concepto de materialismo, como espacios en los que articular el auténtico interés de la filosofía.

Mostrar la falsa apariencia de lo que se presenta como pseudonatural, descifrar su parálisis y poner al descubierto la imbricación dialéctica entre naturaleza e historia que tiene lugar en los fragmentos de lo real serán algunas de las tareas que Adorno asigne a la interpretación materialista. La disolución de la antítesis entre naturaleza e historia a partir de la idea de Naturgeschichte o Historia Natural se interpreta como correctivo a la noción de progreso histórico, al mostrar la libertad y la autonomía de la conciencia como elementos "aún por conquistar". Le corresponde la idea de prehistoria del sujeto, en sentido marxiano, como historia del dominio de la naturaleza interna y externa. Pero, por otro lado, también refleja un tipo de afinidad práctica entre la interpretación filosófica y el materialismo. El "gesto transformador del juego del enigma" expresa el deseo de ahondar en los fragmentos de la realidad sociohistórica para desenmascarar su apariencia de "segunda naturaleza" y mostrarla como una primera oprimida en su interior. La forma de llevarlo a cabo será, siguiendo a Benjamin, la construcción de ideas en constelaciones de conceptos. Pues la interpretación no consiste para Adorno en resolver lo particular en lo general, ni en descubrir un "mundo real" que subyace tras el de los fenómenos. Por el contrario, la filosofía ha de construir "conceptos-llave" capaces de abrir la realidad, como por ejemplo, el de "mercancía". Comprende el concepto de "mercancía" como un "jeroglífico social” en el que se refleja la estructura universal e ideológica de la economía capitalista. Por eso, insiste en el esfuerzo filosófico por descifrar lo singular en la mercancía, para sacar a la luz el antagonismo que representa la totalidad de lo social, lo que significa, finalmente, continuar con los análisis desarrollados por Marx.

Aunque no le dedica ninguna de sus obras, el diálogo con Marx ha de considerarse un momento esencial en la construcción de las tesis materialistas de Adorno. Pues, si bien su filosofía no puede ser comprendida como una repetición, sin discontinuidades, del pensamiento marxiano, sí conserva y amplía algunas de sus líneas maestras, como por ejemplo, la teoría de la mercancía y del dominio 
social, o el fenómeno de la cosificación a partir del análisis del principio de intercambio. Con Marx, leerá la estructura económica de la sociedad burguesa como una estructura de dominio, e interpretará su deseo de liberar a los individuos de los mecanismos coercitivos que impiden su emancipación como el auténtico interés de la tradición materialista. Rehabilitar el componente crítico y liberador de Marx será, pues, uno de los impulsos que articulen la construcción de la filosofía adorniana, un componente que no sólo verá en el diagnóstico del fracaso del sistema capitalista, sino sobre todo en su esfuerzo por hacer cumplir las exigencias de emancipación y de libertad que éste había prometido².

\section{II}

Adorno destacó en numerosas ocasiones la dificultad inherente a la lectura de Marx, mostrando razones que bien podrían ser atribuidas a su propia forma de exponer la filosofía:

cuando se cree que uno puede asimilar a Marx como a cualquier escritor popular porque se ha dirigido al proletariado, resulta completamente imposible de antemano una comprensión correcta del autor. Un presupuesto para comprender una interpretación adecuada del materialismo marxiano sería analizar las cosas en la dificultad y la diferenciación que en él tienen ${ }^{3}$.

2. "Hoy no resulta evidente observar en Adorno a un teórico que haya hecho suya la problemática de la teoría marxiana, que la haya continuado productivamente y ampliado de manera enriquecedora. Mientras que en los años cincuenta y sesenta su teoría fue entendida como un desarrollo originario de la teoría marxiana y como una importante contribución al marxismo occidental (...) actualmente se le desvincula de esta contextualización, algo que ha podido observarse en las celebraciones de su centenario". A. DeMIROvic, Libertad y Humanidad, "Indaga. Revista Internacional de Ciencias Sociales y Humanas" 2 (2004) 6.

3. Th. W. AdoRno, Philosophische Terminologie (Frankfurt, Suhrkamp, 1974) vol. II, 272. En adelante, esta obra será citada con las siglas $P b T$, seguida de número de volumen y de la página correspondiente. 
Aunque su lectura de Marx se inicia en los años de juventud, en este acercamiento será fundamental la relación que mantiene con el Instituto de Investigación Social de Frankfurt y, sobre todo, con Horkheimer. Con sus propios matices diferenciadores, Adorno se inscribe a la orientación materialista que el Instituto había acuñado desde su formación. Pese a las diferencias referidas a cuestiones como la manera de comprender la crítica inmanente, la interpretación de la fenomenología o del papel de las ciencias particulares, la alternativa a la crisis burguesa — que piensan tanto él como Horkheimer- remite a una nueva lectura de la filosofía marxista y del materialismo. Algo que se concretará en el deseo de llevar a cabo una "lógica materialista", como una forma distinta de interpretar la realidad y la teoría a la luz de la crisis de los proyectos idealistas de totalidad y de sentido, pero también ante las lecturas dogmáticas del materialismo histórico.

La llamada Escuela de Frankfurt ocupa un lugar fundamental dentro de los esfuerzos emprendidos en el periodo entreguerras por rehabilitar el marxismo. Se comprende a sí misma como heredera de la filosofía marxista, si bien sus principios teóricos y metodológicos se orientaron al desarrollo de una lectura distinta y no dogmática de la obra de Marx ${ }^{4}$. Y aunque esta orientación se evidenciaba desde los orígenes del Institut, con Carl Grünberg al frente ${ }^{5}$, la incorporación

4. Según HonNETH "la utilización sistemática de todas las disciplinas de investigación de la ciencia social en el desarrollo de una teoría materialista de la sociedad era la finalidad principal de la teoría crítica; así, esperaba superar el prologado purismo teórico del materialismo histórico y hacer posible una fusión fecunda entre la ciencia social académica y la teoría marxista”. A. HonneTH, Critical Theory, en A. Giddens, J. H. Turner, Social Theory Today (Stanford University Press, California, 1987) 349. Otros estudios sobre la posición del Instituto ante la crisis del marxismo se encuentran en D. BÖHLER, Metakritik der Marxschen Ideologiekritiker. Prolegomenon zu einer reflektierten Ideologiekritik und Theorie-Praxis Vermittlung, (Suhrkamp, Frankfurt a.M., 1972); y, más recientemente, E. WALTER-BusCH, Geschichte der Frankfurter Schule: kritische Theorie und Politik (Fink, München, 2010).

5. En su trabajo sobre la Zeitschrift für Sozialforschung, Schmidt aclara algunos de los aspectos de la propuesta de Grünberg en su discurso como primer director del Instituto como, por ejemplo, el rechazo de una concepción materialista de la historia como un sistema metafísico. A. SCHMIDT, Die Zeitschrift für Sozialforschung. Geschichte und gegenwärtige Bedeutung (Kösel, München, 1970) 2. Sobre la historia del Instituto, véase R. Wiggershaus, Die Frankfurter Schule. Geschichte, theoreti- 
de Horkheimer como director aportará un nuevo rumbo en la recuperación de la teoría marxista. La crisis de la sociedad burguesa encontraba su expresión en la del propio pensamiento marxista, convertido en una forma de doctrina oficial de partido y en un sistema dogmático de creencias. Abandonada su comprensión originaria como teoría práctica y revolucionaria orientada a la superación del estado de necesidad y de dominio que generaba la sociedad capitalista, el marxismo termina por adoptar la forma de una metafísica totalitaria incapaz de servir a su verdadero objetivo liberador. Pues estas doctrinas que lo reducían a un conjunto dogmático de respuestas en torno a la historia, la naturaleza o la sociedad, y referidas casi con exclusividad al ámbito económico, representaban el abandono de su perspectiva crítica y emancipadora. Por eso, frente a una perpetuación esclerotizada de su obra, se tratará de comprenderla a la luz de las transformaciones culturales, científicas y sociales del siglo XX.

La necesidad de insistir en las raíces históricas y sociales de la crisis moderna, pero también de enfrentarse teóricamente a los problemas que se habían generado en el pensamiento marxista, llevará a Horkheimer a defender la tradición filosófica ilustrada que había comenzado con Kant y con Hegel, y que ve continuar hasta Marx ${ }^{6}$. $\mathrm{Y}$ es que no sólo ve peligrar el objeto teórico de la filosofía marxiana sino, sobre todo, su alcance crítico en un mundo cuya administración, cada vez mayor y más profunda, impide encontrar resquicios para su superación. Frente a ello, tratará de recuperar la pregunta por la posibilidad de una teoría y una praxis orientada a su propia transformación y la transformación de la realidad:

sche Entwicklung, politische Bedeutung (Hanser, München, 1986); U. MigDAL, Die Frühgeschichte des Frankfurter Instituts für Sozialforschung (Campus Verlag, Frankfurt-New York, 1981); M. JaY, Dialektische Phantasie. Die Geschichte der Frankfurter Schule und des Instituts für Sozialforschung 1923-1950 (Fischer, Frankfurt a.M., 1985); y H. DubIEL, Wissenschaftsorganisation und politische Erfabrung. Studien zur frühen Kritischen Theorie (Suhrkamp, Frankfurt a.M., 1978).

6. Cfr. H-J. Blank, Zur Marx-Rezeption des frühen Horkheimer, en I. Fetscher, A. SсHмidT (eds.), Emanzipation als Versöbnung. Zu Adornos Kritik der Warentausch-Gesellenschaft und Perspektiven der Transformation (Verlag Neue Kritik, Frankfurt a. M., 2002) 53. 
[La Teoría Crítica] intenta vincularse a la gran tradición occidental, aquella que en Europa ha tenido su repercusión crítica o ha sido completamente aniquilada. Con eso se ha pensado, sobre todo, en la Ilustración francesa e inglesa, y en el idealismo clásico alemán hasta Marx. Para conservar vivos los elementos de esa tradición no basta su simple repetición y su mecánica aplicación en el presente, sino el perfeccionamiento positivo por medio de la utilización de los conocimientos más modernos de todos los ámbitos del saber. Los conceptos deben ser continuamente enriquecidos por nuevas experiencias y adaptados a la situación histórica transformada ${ }^{7}$.

La filosofía de Marx se convierte en la fuente principal de reflexión en los trabajos del Instituto pues, a diferencia de otras explicaciones encubridoras y legitimadoras de lo real, sus ideas permiten una comprensión adecuada de los mecanismos que subyacen a la crisis y, como consecuencia, también una transformación y superación de la misma ${ }^{8}$. Se trata de ver en la independencia de las relaciones económicas y sociales, en el "libre juego" de las fuerzas económicas, la causa del dominio y del control al que se ven sometidos los individuos y que, en última instancia, impiden el desarrollo pleno de sus potencialidades y la posibilidad de alcanzar una organización de la sociedad auténticamente racional. Esto supone, por tanto, rechazar la identificación con las formas ortodoxas y metafísicas del marxismo, así como la hipóstasis de identidades

7. M. HorkHeimer, Gesammelte Schriften (Fischer, Frankfurt a.M., 1985) vol. 12, 143-144. En adelante, la obra de Horkheimer será citada con las siglas $H G S$, seguida del número de volumen y la página correspondiente.

8. Esta idea será constante en la obra de Horkheimer, tal como se muestra en una conversación con Hersche de los años sesenta, en la que revisa algunos aspectos de su inicial comprensión del marxismo: "en gran parte, estábamos de acuerdo teóricamente con el marxismo, pero nos horrorizaba que los comunistas prácticamente coincidieran con los nacionalsocialistas (...) El marxismo significaba para nosotros una teoría de la sociedad, pero la auténtica política sobre la realización de lo que Marx había denominado la sociedad correcta, no era lo que había decidido entonces el partido comunista" (M. HorkHEIMER, Dokumente-Stationen. Gespräch mit Otmar Hersche, en HGS, vol. 7, 328). 
colectivas como "espíritu", "clase" o "pueblo". El pensamiento de Marx deja de tomarse como un corpus teórico definitivo, para hacerlo como una teoría cuyas limitaciones exigen ser revisadas, a fin de buscar el rearme de su potencialidad crítica. Leer el materialismo marxiano, no como dogma, sino en medio del diagnóstico de una situación falsa que ha de ser revocada, implica reivindicar sus principios originales. Unos principios que convergen en la crítica concreta e inmanente a las relaciones sociales cosificadas y cosificadoras. Pues, como asegura Horkheimer, el mérito de la filosofía marxiana consiste en "haber descubierto la ley del orden inhumano dominante y en mostrar la palanca de la que hay que servirse para crear uno más humano" 10 .

El interés por desarrollar una teoría crítica de lo social de inspiración marxiana orientada a la denuncia y a la superación de las formas de control que pesan sobre el individuo, constituye también el núcleo de la obra de Adorno y lo situará en la misma línea de pensamiento de Horkheimer. Esta coincidencia se puso de manifiesto en las discusiones que los miembros del Instituto habían llevado a cabo durante los años treinta acerca de la forma adecuada de comprender la dialéctica materialista y el método de análisis marxiano ${ }^{11}$. Lo que se desprende de estas conversaciones es la idea, cada vez más consolidada, de que sólo una teoría materialista de la historia y de lo social sería capaz de explicar las causas históricas y sociales de la crisis y, lo que resulta aún más importante, de retomar los impulsos críticos y liberadores de la tradición ilustrada. Por eso, coinciden en rechazar la dialéctica oficial marxista y su comprensión del materialismo como una concepción cerrada del mundo, o simplemente como una corriente de pensamiento esclerotizada contraria al idealismo. Éste paraliza sus términos verdaderamente importantes y lo convierte en una "religión de Estado".

9. Cfr. M. Gangl, Politische Ökonomie und Kritische Theorie. Ein Beitrag zur theoretischen Entwicklung der Frankfurter Schule (Campus Verlag Frankfurt/New York, 1987).

10. HGS, vol. 2, 342 .

11. Cfr. Die Marxsche Methode und ihre Anwendbarkeit auf die Analyse der gegenwärtigen Krise. Seminardiskussionen, en HGS, vol. 12, 398-416. 
Frente a estas interpretaciones empobrecidas, Adorno insiste en comprender el materialismo como un método crítico, o como había apuntado Benjamin, como "una infraestructura política y filosófica"12. Así, pues, la filosofía marxiana "no aparece como una teoría metafísica, ni siquiera negativamente metafísica, sino que se mueve, dicho en términos kantianos, dentro de lo ya constituido"13. Leer las tesis materialistas de Marx como herederas de la tradición idealista, de los "impulsos de la dialéctica de 1800", supone ahondar en el deseo de restituir la fuerza crítica y revolucionaria de sus análisis de los fundamentos de la sociedad burguesa; es decir, en palabras de Horkheimer, de "mantener el impulso radical del marxismo y de la ilustración entera"14.

\section{III}

La recepción de la filosofía de Marx por parte de Adorno vendrá condicionada por su interpretación específica de la tradición materialista. $\mathrm{Y}$ es que al igual que considera un error comprender el materialismo como una teoría del conocimiento cerrada, también cree que los conceptos y principios del pensamiento marxiano han de ser revisados desde su referencialidad histórica. Es necesario resaltar aquí el interés que pervive en su obra, desde sus textos más tempranos, por rescatar una comprensión de las tesis materialistas que queden liberadas de sus formulaciones dogmáticas, poniendo de relieve sus elementos prácticos y emancipadores. Por ello, insiste en la investigación acerca del tema "auténticamente materialista" de Marx que lo diferencie de las concepciones materialistas vulgares; una cuestión cree ver oculta hasta el momento, entre falsas alternativas.

Desde sus primeras obras, Adorno entiende el materialismo, también el de Marx, como una tradición filosófica denigrada y olvidada. Se queja de la escasa atención que ha tenido para el pensamiento contemporáneo, que con frecuencia lo ha reducido a una

12. Th. W. Adorno, W. Benjamin, Briefwechsel 1928-1940 (Suhrkamp, Frankfurt a.M., 1994) 164.

13. PhT, vol. II, 216.

14. $H G S$, vol. 12,598 . 
cosmovisión o teoría del conocimiento. Por eso, su filosofía puede ser entendida a partir del deseo de rescatar lo que considera un impulso materialista contrario al pensamiento de la totalidad, que le impide convertirse en una metafísica o posición ontológica. Aunque esta idea se ha ido perfilando en sus primeros trabajos académicos, uno de los lugares donde mejor se resume su lectura del materialismo marxiano y en el que se apuntan la mayoría de los rasgos específicos de su forma de comprender la filosofía, son las lecciones que pronuncia en la Universidad de Frankfurt en los años sesenta, y que han sido publicadas con el título Terminología filosófica. En ellas, insiste en romper con la praxis clasificadora que tiende a reducir cualquier filosofía a un principio que la englobe y que, en el caso del materialismo, acentúa su comprensión esclerotizada como sistema filosófico contrario al idealismo.

"Pertenecen al materialismo cosas tan divergentes como el atomismo fisicalista de Demócrito y su antecesor Leucipo", señala, "también en cierto modo el modelo del pensamiento teórico físico moderno y, por otra parte, el materialismo dialéctico de Marx"15. Esta pluralidad de versiones que dificulta la señalización de un corpus de temas y categorías exclusivas del materialismo, apunta a la necesidad de entenderlo en una diversidad de formas y de contenidos que surgen como resultado de la toma de posición, también distinta, ante los problemas históricosociales. No obstante, partiendo de lo que entiende como "aroma materialista"16, señala dos tendencias comunes a las formas en las que se ha presentado el materialismo a lo largo de la historia. De un lado, una tendencia crítica y desenmascaradora, que entiende como límite ante el idealismo y su representación del espíritu absoluto. De otro lado, una tendencia dogmática inherente a cualquier planteamiento materialista y que lo liga a la

15. $\mathrm{PhT}$, vol. II, 169 .

16. Sobre esto, aclara: "he elegido la expresión aroma no sólo por la necesidad de encontrar la palabra exacta. Recuerda cualidades fisiológicas sensitivas de las que no se puede prescindir cuando se quiere intentar captar lo específico que conviene a todos los conceptos del materialismo, incluso cuando se piensa en el complejo total de lo que es el materialismo en el sentido más amplio, con toda suerte de conexiones impetuosas y de polémicas despiadadas entre las diferentes y apasionadas posiciones materialistas" (PhT, vol. II, 171). 
"antigua tradición precrítica de la filosofía, la hilozoísta". Y es que en su intento de desenmascarar el momento ilusorio que se esconde en las filosofías del espíritu, termina por comprender el acceso a la realidad como algo inmediato. Por eso,

no recurre primero al sujeto por el que se constituye el conocimiento, sino que se refiere inmediatamente a la realidad misma como protesta contra el momento ilusorio del espíritu (...) El materialismo tiene siempre, y en todas su versiones, cierto momento de retraso, de rusticidad, frente a las filosofías elegantes y refinadas. No pretende la finura, sino que busca el verdadero material, como hicieron en algún lugar sus primeros padres. Lo cual puede conducir en determinadas ocasiones a la decadencia del materialismo, que degenera en ideología, en barbarie ${ }^{17}$.

En la expresión "decadencia del materialismo" se encuentra contenido su deseo constante de separarse de las llamadas concepciones vulgares de la filosofía materialista, afanadas en la reducción a lo material como lo primero inmediato. Este materialismo puro, monístico y metafísico termina convertido en una concepción del mundo dogmática basada en la "teoría del reflejo" en la que las sensaciones se entienden como copias idénticas a los datos de la realidad y, lo que es más importante, como fuente de su justificación.

\section{IV}

Adorno da continuidad a algunas de las ideas que, unas décadas antes, había defendido Horkheimer en dos importantes artículos: "Materialismo y metafísica" y "Materialismo y moral"18. En ellos la

17. PhT, vol. II, 130 .

18. Ambos trabajos, de 1933, se encuentran publicados en $H G S$, vol. 3. Unos años antes de la aparición de estos artículos, Horkheimer había publicado una reseña sobre la obra de Lenin Materialismo y empiriocriticismo, a la que consideraba un ejemplo de interpretación ingenua del realismo que niega el papel activo del sujeto y que reduce el materialismo a una teoría del conocimiento mecanicista. El texto de la reseña se encuentra publicado en el volumen 11 de las obras completas de Horkheimer. 
tradición materialista se comprende no sólo como el ámbito histórico-filosófico en el que desarrolla su proyecto de investigación social. Se trata, además, del lugar específico desde el que cree posible enfrentarse al hundimiento del mundo moderno, conocer las causas de su crisis y la posibilidad de su revocación. Al mismo tiempo insiste en delimitarlo tanto frente a formulaciones toscas que olvidan su dimensión propiamente emancipadora y práctica, como frente a las nuevas lecturas metafísicas que lo reducen a una concepción del mundo. $\mathrm{Y}$ es que no trata de convertirse en un sistema alternativo al del espíritu autónomo, sino que, por el contrario, se dirige precisamente contra la pretensión de sistema. Por eso, no es posible identificarlo con una forma de metafísica que ponga sobre la base la tesis de una prioridad ontológica de lo material.

Se evidencia el interés de Horkheimer por alejarse de las fórmulas naturalistas y cientificistas aparentemente contrarias a la filosofía materialista. En ellas ve la adopción de un materialismo vulgar que caracteriza el mundo físico como un mero contexto mecanicista de objetos. Frente a este planteamiento, se trataría de elaborar una lectura dialéctica del marxismo que, si bien reconozca la imposibilidad de seguir manteniendo el principio idealista de la razón absoluta, tampoco ignore el papel activo del sujeto en la filosofía. Por eso, la diferencia entre idealismo y materialismo no estriba en la toma de posición sobre la relación entre el ser material y la conciencia individual, sino en la forma de comprender y tratar el problema de la finitud, de la transitoriedad y, en última instancia, también del dolor. Pues, si bien el materialismo lo entiende como un hecho aceptable en sí mismo, la metafísica trata de socavarlo y de esconderlo. Por eso, Horkheimer considera la actitud materialista como la más adecuada para reflejar los auténticos esfuerzos por revocar las condiciones de vida existentes y por proponer su transformación y mejora ${ }^{19}$.

19. Aguilera señala sobre esto: "ya se denomine filosofía social, materialismo interdisciplinario, teoría crítica o incluso anhelo de lo otro (o teología materialista), se trata de una incursión en el pensamiento de lo somático, del estrato torturado en los seres humanos por el avance de una historia que no marcha por su mejor lado". A. Aguilera, Introducción, en M. HoRKHEIMER, Autoridad y familia, y otros escritos (Paidós, Madrid, 2000) 19. 
La filosofía materialista comprende el sufrimiento como un estado que ha de ser superado. De ahí que el interés que guíe al programa de la Teoría Crítica sea el de liberar a los individuos de ese estado y contribuir a su emancipación. Una emancipación que, además, se torna imposible sin la atención a los procesos de transformación que tienen lugar en la estructura económica y social. Por eso, señala Horkheimer, "el materialismo del presente no se caracteriza por unos rasgos formales que se tienen que destacar frente a la metafísica idealista, sino por su contenido: la teoría económica de la sociedad" 20 . Cree necesario, de esta forma, destacar la abolición de la injusticia social y el establecimiento de los medios que hagan posible el cumplimiento de los intereses humanos como los principales elementos que unen su filosofía materialista con la tradición burguesa ilustrada:

el materialismo de la burguesía temprana se dirigía al rearme del conocimiento de lo natural y a la obtención de nuevas fuerzas para el dominio de la naturaleza y de los hombres. Pero la miseria del presente se encuentra conectada con la estructura social. Por ello, la teoría de la sociedad representa el contenido del materialismo actual ${ }^{21}$.

Estas ideas son compartidas con modulaciones por Adorno cuando rechaza tomar parte del clásico debate abierto por los materialistas del siglo XIX en torno a la prioridad de la materia o del espíritu. Lo que encuentra aquí es, en última instancia, el deseo de fijar un elemento que actúe como fundamento a partir del cual poder referir y explicar la multiplicidad de los fenómenos en una teoría del conocimiento. Ya en sus trabajos sobre Husserl había insistido en la definición de crítica materialista e inmanente al idealismo como rechazo de la prima philosopbia. Hacía alusión a la búsqueda constante en la historia del pensamiento de un principio originario desde el que se pretende derivar el resto de la comprensión de la realidad, ya

20. $H G S$, vol. 3, 104-105.

21. $H G S$, vol. 3,84 . 
sea a través de la apelación idealista a "lo alto" o al espíritu, como a "lo bajo", relacionado con lo material, lo natural múltiple e inarticulado. Por el contrario, Adorno no adopta como alternativa en su confrontación con las corrientes metafísicas la defensa del carácter inmediato de lo material. Pues su filosofía representa el esfuerzo contrario a toda forma de "filosofía primera", ya sea sobre la base de un sujeto absoluto concebido a la manera idealista, como sobre la idea de una ontología materialista del ser social. Por eso, frente a la oposición radical entre idealismo y materialismo, considerará a ambos en el desarrollo y desenvolvimiento inmanente de sus categorías, y los entenderá mediados entre sí y referidos desde su interior a momentos del otro ${ }^{22}$. Reconoce la oposición materialista frente al idealismo en su toma de partido por la determinación material de la realidad y en el rechazo a entenderla como el producto de un espíritu absoluto. En esto consiste el componente desenmascarador del materialismo, pues muestra el engaño que supone el primado del espíritu y le opone su necesario arraigo material ${ }^{23}$. Sin embargo, la absolutización del momento material y el olvido de la espontaneidad del sujeto conducen a un engaño todavía más peligroso, que termina por hacer retroceder al materialismo a una situación de barbarie idéntica a la que pretendía superar. $\mathrm{Al}$ afirmar como única realidad la materia inmediata e indiferenciada se ve forzado a convertirse en un sistema de pensamiento, y la teoría, en una copia inmediata de la realidad ${ }^{24}$. Por eso, frente a los intentos dogmáticos por afirmar

22. En una carta dirigida a Adorno, escribe Horkheimer: "considero como algo de gran importancia explicar la diferencia entre idealismo y materialismo en atención a las distintas formas de planteamiento que existen en ambos casos". Th. W. Adorno, M. HorkHeimer, Briefwechsel 1927-1937 (Suhrkamp, Frankfurt a. M., 2003) vol. 1, 11-12.

23. Schmidt concibe el materialismo adorniano como "una forma de pensamiento detectivesca, de crítica y diagnóstico". A. SCHMIDT, Begriff des Materialismus bei Adorno, en L. Friederburg, J. Habermas (eds.), Adorno-Konferenz 1983 (Suhrkamp, Frankfurt a.M., 1999) 14. Una revisión ampliada de este artículo se encuentra en A. SCHMIDT, Adornos Spätwerk: Übergang zum Materialismus als des Nichtidentischen, en I. FETSCHER, A. SCHMIDT (eds.), Emanzipation als Versöhnung. Zu Adornos Kritik der Warentausch. Gesellenschaft und Perspektiven der Transformation (Neue Kritik, Frankfurt a. M., 2002) 89-109.

24. "La dialéctica negativa no es ni un método estricto ni tampoco un reflejo de la realidad. No es método porque la cosa irreconciliada, a la que le falta esa identi- 
el acceso a la materia como lo inmediato y que llevan aparejada una "teoría del reflejo" que comporta la creencia en un sujeto capaz de captar la realidad de forma completa, Adorno insiste en la necesidad de los desiderata filosóficos para la teoría materialista:

la teoría materialista no puede prescindir de los desiderata filosóficos si no quiere caer en el mismo provincianismo que desfigura el arte en los estado del Este. El objeto de la teoría no es algo inmediato, cuyo molde puede llevarse a casa. El conocimiento no posee, como la policía del Estado, un álbum de sus objetos. Más bien éstos los piensa en su mediación, pues de lo contrario, se conformaría con la descripción de la fachada ${ }^{25}$.

Lo que le ayuda a alejarse de una claudicación en la materia es la determinación dialéctica que imprime a sus tesis materialistas. La concepción materialista y dialéctica de su filosofía no pasa por la absolutización del momento material sobre la conciencia, sino por entender la mediación que se encuentra en ambos. En este sentido, su diálogo con la filosofía de Marx no sólo se realiza sobre la base de la comprensión que encuentra en ella de la estructura social objetiva sino, lo que es más importante, a la luz del cambio práctico que incluye su propia superación. Verá el análisis marxiano de la mercancía y del principio del intercambio que se lleva a cabo en $E l$ capital como el lugar en el que anclar la comprensión de la designación materialista de su filosofía. Pues en este análisis no sólo ve la afirmación positiva y el reconocimiento de la materialidad frente al idealismo absoluto (el "recuerdo de la naturaleza en el sujeto", tal como se expresaba en Dialéctica de la Ilustración), sino que además contiene el momento de protesta ante la negatividad del mundo ${ }^{26} . \mathrm{Y}$

dad que exige el pensamiento, es contradictoria (...) No es reflejo, porque el pensamiento no es una reproducción de la cosa, sino que se dirige a ella sin imágenes. La intención ilustrada del pensamiento, la desmitologización, elimina el carácter de copia de la conciencia”. Th. W. Adorno, Ontologie und Dialektik. 1960-61 (Suhrkamp, Frankfurt a. M., 2002) 333.

25. AGS, vol. 6, 206.

26. En una carta a Pollock, Horkheimer entiende como "el descubrimiento más molesto al que conduce el materialismo el hecho de que la razón sólo existe en la 
precisamente en esto consiste el "sentido enfático" del materialismo que Adorno trata de hacer suyo.

\section{$\mathrm{V}$}

Adorno asume la problemática de la teoría marxiana de la mercancía - que considera un "pedazo de la herencia de la filosofía clásica alemana" ${ }^{27}$ - y del dominio social, pues comprende el principio de intercambio como el elemento determinante en el análisis de la sociedad burguesa. Sin embargo, la importancia que le atribuye como componente central de su teoría de lo social tiene como antecedente sus primeros trabajos. Ya en su habilitación sobre Kierkegaard había prestado atención a lo que llamaba "la memoria de la mercancía" y a su representación en Marx: "esta categoría guarda, como quintaesencia de la conexión entera de todos los fenómenos de la sociedad capitalista, la memoria de la totalidad" ${ }^{28}$. Durante los años treinta se ocupa de la relación entre el fetichismo de la mercancía, la universalización del principio de intercambio y la obra de arte a la luz del fenómeno benjaminiano de la "pérdida del aura". El Pasaggen-Werk de Benjamin pretendía realizar una protohistoria del siglo XIX que tuviera como punto de partida la categoría marxiana del carácter fetichista de la mercancía para explicar la influencia de la economía capitalista sobre la cultura tradicional. Pues consideraba los pasajes parisinos como los lugares de exposición, no sólo de

medida que tras de sí tiene un sujeto natural. Ella está dada a este sujeto natural en tanto quiere hacer uso de ella" (M. HORKHEIMER, Briefwechsel 1937-1940, en $H G S$, vol. 16, 235).

27. $A G S$, vol. 6, 190 .

28. Th. W. Adorno, Kierkegaard. Konstruktion des Ästhetischen, en AGS, vol. 2, 151. Pese a que el interés bibliográfico por esta obra ha sido escaso, es posible señalar algunos monográficos que le han prestado atención como momento central para el desenvolvimiento de su pensamiento, entre ellos: H. DEusEr, Dialektische Theologie: Studien zu Adornos Metaphysik und zum Spätwerk Kierkegaards (Kaiser, München, 1980); V. GómEZ, El pensamiento estético de Theodor W. Adorno (Cátedra, Valencia, 1998); y J. A. Zamora, Th. W. Adorno. Pensar contra la barbarie (Trotta, Madrid, 2004). Por su parte, Tillich escribe una reseña sobre la aparición de la obra de Adorno: Cfr. Kierkegaard: Konstruktion des Aesthetischen, Reviewed by P. Tillich, "The Journal of Philosophy" XXXI/23 (1934) 640. 
los productos que generaba el sistema de consumo capitalista, sino también de las ruinas que representaban los productos que habían caído en desuso. En ellos quedaba expresa la glorificación del valor de cambio de las mercancías como una "fantasmagoría en la que intervienen los hombres para desvanecerse a sí mismos"29.

Si bien Adorno parece alabar el diagnóstico del carácter fantasmagórico de la cultura capitalista moderna, también mostró desde el principio su desacuerdo con algunos de los planteamientos sostenidos por Benjamin ${ }^{30}$. No acepta la idea de que el montaje de materiales textuales del pasado pudiese por sí sólo, y sin elaboración teórica, provocar un desciframiento de los objetos del pasado. Rechaza comprender las imágenes dialécticas como formas en las que es posible captar el carácter fetichista de la conciencia colectiva. Pues lo problemático en la obra de Benjamin es, en sus palabras, "concebir la imagen dialéctica como un contenido de conciencia aunque sea colectivo, referirla linealmente -incluso diría históricoevolutivamente- a un futuro comprendido como utopía, y entender la época precisamente como el sujeto unificado en sí mismo" 31 .

Estas líneas conectan con su concepción materialista de interpretación de lo concreto en la que los fenómenos sociales son considerados elementos en los que descifrar las tendencias dominantes de lo social. Una idea que se repite en el que fuera su primer artículo en la Zeitschrift für Sozialforschung, publicado con el título "Sobre la situación social de la música”. El texto parte de la transformación de la música en mercancía como consecuencia de la abstracción de su valor de uso que tiene lugar dentro del sistema capitalista, cuando no se somete a las condiciones exigidas por el mercado. Sin embargo, lejos

29. W. Benjamin, Paris, die Hauptstadt des XIX. Fabrhunderts, en Gesammelte Schriften (Suhrkamp, Frankfurt a.M., 1991) vol. V/I, 50.

30. Para un análisis de las objeciones al texto de Benjamin, véase los trabajos de H. H. Holz, Von Kunstwerk zur Ware. Studien zur Funktion des ästhetischen Gegenstands im Spätkapitalismus, (Luchterhand, Neuwied/Berlin, 1972); J. FredeL, Kunst als Produktivkraft. Kritik eines Fetischs am Beispiel der Asthetische Theorie Theodor W. Adornos, en M. MüLlER, Autonomie der Kunst, (Suhrkamp, Frankfurt a. M., 1972); y J. A. ZAMORA, El concepto de fantasmagoría. Sobre una controversia entre $W$. Benjamin y Th. W. Adorno, "Taula" 31-32 (1999) 129-151.

31. Th. W. Adorno, W. Benjamin, Briefwechsel 1928-1940, op. cit., 140. 
de ver en esta situación una excusa para exigir su abolición, Adorno encuentra en ella un momento de resistencia y de crítica. Pues la "pérdida del aura" no exige su restauración, como creía Benjamin, sino precisamente su asimilación a la mercancía. En su estructura, la música presenta las antinomias de la totalidad social, de ahí que su alienación constituya un reflejo de su autonomía y de la necesidad de reivindicar para ella un contenido cognoscitivo propio.

Aunque años después reconocerá el error que presenta el artículo al equiparar sin mediación el concepto de producción musical con la prioridad de la esfera económica de producción, en él se recogen algunos de los temas que determinarán tempranamente su relación con el materialismo dialéctico y con el análisis de la mercancía. Ya en La actualidad de la filosofía había prestado atención al concepto marxiano de mercancía vinculándolo a su definición de interpretación materialista. La tarea de la filosofía consiste en prestar atención a las figuras de la realidad carentes de intención o, con Freud, a la "escoria del mundo de los fenómenos". Se trata de comprender las cifras enigmáticas de lo existente agrupando distintos elementos del análisis social para dar lugar a una forma concreta, en la que quede al descubierto cada uno de sus momentos particulares. La filosofía construye "llaves" con las que abrir la realidad, y la mercancía será una de ellas, cuyo desciframiento permite explicar lo universal de la economía capitalista — la ley del valor-y, con ello, la raíz ideológica de la sociedad.

\section{VI}

En la figura histórica de la mercancía encuentra "la estructura de una realidad en cuyo sentido oculto indagó en vano la investigación del problema de la cosa en sí" 32 . Sin embargo, Adorno no se habría limitado a considerar su análisis como un ejemplo de la dirección en la que ve las tareas de la interpretación filosófica, sino que le otorga un lugar central en su concepción materialista de la dialéctica. Pues de él se desprende la interpretación del intercambio y de la cosifi-

32. Th.W. Adorno, Die Aktualität der Philosophie, en AGS, vol. 1, 337. 
cación como factores determinantes en la articulación de su teoría de lo social. El fenómeno de la cosificación no puede ser referido con exclusividad al problema de la conciencia, como habría hecho Lukács en Historia y conciencia de clase ${ }^{33}$. No sólo expresa el estado de parálisis de las instituciones o de los procesos de pensamiento, sino de qué manera la racionalidad del intercambio en la sociedad capitalista se convierte en el modelo social del principio de identidad ${ }^{34}$. Pues, como le habría objetado a Benjamin, el carácter fetichista de la mercancía no es un hecho de conciencia, sino dialéctico, en tanto que produce conciencia: es la forma de reflexión que tiene ante sí la falsa conciencia. Por eso, sus consideraciones en torno a estas ideas no se realizan con exclusividad sobre la base de una crítica a la economía política, sino que se interpretan alegóricamente como causa y fundamento del "mal social" 35 . Este es un aspecto central para comprender su lectura del materialismo de Marx y la forma en la que reelabora los principios y conceptos fundamentales de su crítica a la economía política. Se trata de la definición de la ley de intercambio como índice de una "mediación universal radical" o "generalidad abstracta" que surge como consecuencia de la subsun-

33. Pese a no compartir la interpretación metafísico-hegeliana del materialismo de Lukács, Adorno lo comprende como un importante correctivo a las interpretaciones ortodoxas y dogmáticas del marxismo. Además, le reconocerá ser el primero en haber prestado atención a la importancia del concepto de cosificación y de abstracción en la filosofía marxiana. Para un análisis de la influencia de la obra de Lukács sobre la rehabilitación de la dimensión filosófica del marxismo, véase L. KolaKowsKI, Die Hauptströmmungen des Marxismus. Entstehung-EntwicklungZerfall (Piper, München, 1979).

34. Grenz afirma: "el concepto crítico de cosificación es desarrollado por Marx, reconocido por Lukács y examinado en un sentido más avanzado por Adorno, convertido en factum social". F. Grenz, Adornos Philosophie in Grundbegriffen. Auflösung einer Deutungsproblem (Suhrkamp, Frankfurt a. M., 1974) 252.

35. Link señala la manera en la que "el principio de intercambio proporciona a Adorno contenidos teóricos-cognoscitivos, psicológicos y económicos, al sobrepasar el principio de explicación marxista limitado a la etimología economicista". T. LINK, Zum Begriff der Natur in der Gesellschaftstheorie Theodor W. Adornos (Böhlau, $\mathrm{Köln} / \mathrm{Wien}, 1986$ ) 26. Una tesis similar se encuentra en el trabajo de C. GöRG, Zwischen Tauschgesellschaft und Wertgesetz Adornos Gesellschaftskritik und die beutige Globalisierungsdiskussion, en J. BECKER, H. BRAKEMAIER (eds.), Vereinigung freier Individuen. Kritik der Tauschgesellschaft und gesellschaftliches Gesamtsubjekt bei Theodor W. Adorno (VSA, Hamburg, 2004). 
ción de lo particular en lo general a través de las leyes sociales. Por eso, a diferencia del carácter restrictivo de Lukács, el intercambio se convierte para Adorno en una categoría histórica-universal que encuentra su origen en el movimiento ilustrado del sujeto frente a la naturaleza:

La abstracción del principio de intercambio se relaciona con el dominio de lo general sobre lo particular, de la sociedad sobre sus miembros. Por tanto, no es neutral. En la reducción de los individuos a agentes y portadores del intercambio de mercancías se esconde el dominio del hombre sobre el hombre. Eso permanece como algo cierto, pese a todas las dificultades a las que se enfrentan algunas de las categorías de la Crítica a la economía política ${ }^{36}$.

Si Marx había atendido a los antagonismos y las contradicciones de la sociedad capitalista a partir del estudio de la racionalidad del intercambio, Adorno situará sus análisis en una dialéctica más general que incluya los momentos no económicos del dominio. Esto significa prestar atención tanto a las antinomias de la racionalidad económica como, sobre todo, a aquellas que se generan en la propia racionalidad dominadora de la naturaleza ${ }^{37}$. Con ello pone de relieve la tendencia de la sociedad moderna hacia formas totalitarias en las que los individuos acaban por perder su individualidad al ser sometidos a la totalidad y objetividad social. Esto le permite ver en el intercambio no sólo la causa de la cosificación, sino también la protesta contra la transformación de lo histórico

36. $A G S$, vol. 8,13 .

37. "El principio de intercambio se convierte en el fundamento para el análisis del mundo de vida burgués. La identificación del trabajo humano y de sus productos en medidas de valor cuantitativas se encuentran en relación con la descualificación de los sujetos (...) La relación entre intercambio y dominio se extiende en la conciencia como dominio de las ideologías". T. LINK, Zum Begriff der Natur in der Gesellschaftstheorie Theodor W. Adornos, op. cit., 120. Esta misma idea la comparte Ritser, pues ve en este concepto una "referencia central" para la teoría crítica adorniana. J. RiTSER, Ein zu recht abgewertetes Thema der Kritischen Theorie?, en C. GÖRG, R. RoTH (eds.), Kein Staat zu machen. Zur Kritik der Sozialwissenschaften (Westfälisches Dampfboot, Münster, 1998) 324. 
en lo "mítico paralizado"38. Lo que significa, en última instancia, atender a un impulso de superación inmanente a la propia teoría de la mercancía. Por eso, su crítica no se dirige al principio de intercambio como tal, pretendiendo su definitiva abolición, sino a la abstracción que tiene lugar en él y que desarrolla una forma específica de subjetividad que acaba por sustraer al individuo la autonomía que creía defender. Apunta, pues, al principio de equivalencia e identidad.

En la reducción del mundo a una totalidad idéntica a sí misma persiste un momento utópico que Adorno interpreta como la voluntad de convertir lo distinto en igual. Por eso, no entiende la abolición definitiva del intercambio como una restitución inmediata de la libertad sino, por el contrario, como la recaída en la antigua injusticia. Su eliminación también significaría la abolición de la mediación y, por consiguiente, la reproducción de una apropiación inmediata: "la crítica al intercambio como el principio identificador del pensamiento quiere la realización del ideal de cambio libre y justo, que no se ha cumplido. Sólo eso trascendería el canje" ${ }^{39}$. Pues únicamente en la sociedad del intercambio ve posible encontrar el potencial emancipador y socializador del concepto de trabajo: "el cumplimiento del contrato de cambio, constantemente quebrantado, convergería con la abolición del contrato. Si de verdad se intercambiasen equivalentes, el cambio desaparecería. El verdadero progreso con relación al intercambio no establece meramente otro, sino también a éste, reconciliado consigo mismo" ${ }^{40}$. Lo que se desprende de estas líneas es la defensa de una nueva concepción de las relaciones sociales en la que desaparecería el carácter fetichista de

38. Köhler ve en el concepto de segunda naturaleza "la dimensión de protesta contra la relación de la razón en sí misma”. H.G. KöHLER, Th. W. Adornos Konstruktion einer kritischen Theorie der Gesellschaft (Universidad, Berlín, 1974).

39. AGS, vol. 6, 150.

40. Th. W. Adorno, Fortschritt, en $A G S$, vol. 10.2, 637. Demirovic señala al respecto que "considerar a Adorno como un resignado teórico de la subsunción implica, precisamente, pasar por alto su defensa del intercambio y la identidad, ya que en éstos ve los fundamentos de la dinámica social hacia la igualdad, de la superación de las relaciones capitalistas de la producción y del principio del intercambio como tal". A. Demirovic, Libertad y Humanidad, op. cit., 13. 
la mercancía, puesto que el valor de cambio dejaría de aparecer bajo una forma cosificada y objetualizada, como un en-sí.

El tratamiento dialéctico de los conceptos de "cosificación" y de "intercambio" que tiene lugar en la obra de Adorno influirá también en la forma de entender el problema de la emancipación. Su materialismo rechaza la confianza "excesivamente idealista" ante una identificación del sujeto consigo mismo como sujeto-objeto de la historia, que conduzca a la revolución y, como consecuencia, a la desaparición de la alienación. Se trata, como dirá, de una "reconciliación falsa y extorsionada" ${ }^{41}$. La esperanza de resistir dentro de la sociedad administrada se encuentra en la individuación del conocimiento, en la capacidad del sujeto para experimentar lo particular y para rechazar cualquier tipo de identidad o de reconciliación con las contradicciones y, finalmente, para reconocer su dependencia respecto a las condiciones sociales determinantes. Por eso, si para Lukács el concepto contrario al de "cosificación” era el de "conciencia de clase", para Adorno será el de "experiencia". No significa, sin embargo, la defensa de una suerte de individualismo, ni tampoco de una idea de sociedad como suma de átomos, o en palabras de Horkheimer, como un "alma de masas". Ya desde su escrito sobre Kierkegaard había insistido en el peligro que encuentra en la apelación a la interioridad subjetiva como recurso para acceder a la libertad. Si la hegemonía del colectivo social impide la individualización de la voluntad de decisión respecto al grupo, también la de lo individual cae en el error de no tener en cuenta el carácter histórico de las formas de pensamiento.

Cualquier esperanza ante la posibilidad de un "socialismo humanista" se va desvaneciendo con el desarrollo de las nuevas formas de dominio generadas en los acontecimientos sociales y políticos en Europa. El predominio de la lógica del capitalismo avanzado y su tendencia opresiva y desintegradora sobre todos los aspectos de la vida — al que se referían con el término "mundo administrado"

41. Th. W. Adorno, Erpresste Versöhnung, en AGS, vol. 11, 278.

42. M. HorkHeImer, Die verwaltete Welt, oder: Die Krisis des Individuums, en HGS, vol. $13,121$. 
ponía de manifiesto la necesidad de una revisión de la filosofía marxiana, tanto de sus categorías sobre la economía política, como de su perspectiva excesivamente optimista. Pues los nuevos acontecimientos que habrían denunciado en Dialéctica de la Ilustración no sólo desmienten la esperanza en el proletariado como sujeto-objeto de la historia, sino también las exigencias prácticas de la teoría que se encuentran en el materialismo emancipador de Marx.

\section{VII}

La necesidad de una revisión de los presupuestos marxistas orientada a la pregunta por las causas que han provocado el incumplimiento de sus pronósticos será una preocupación constante en Adorno y su proyecto de una lógica materialista, ahora atravesada por las consecuencias que le habría impuesto los resultados de la dialéctica de la modernidad. $\mathrm{Y}$ es que la insistencia en la referencialidad histórica del marxismo impide entenderlo como un sistema cerrado, pero también permite rehabilitar el contenido crítico y utópico de su materialismo dialéctico ${ }^{43}$. Aunque el estudio de la economía política había ocupado un lugar central en las tareas del Instituto, el acento se situará progresivamente en la crítica a la civilización y a la racionalidad sobre la que se asienta. Seguirán viendo en la base económica un componente esencial del funcionamiento de la sociedad capitalista, pero su crítica será ejercida desde la propia determinación histórica de sus temas y categorías, y su adaptación a las condiciones materiales del presente, lo que impide finalmente repetir el lastre metafísico y dogmático de las anteriores representaciones del marxismo ${ }^{44}$.

43. A este respecto, Schmidt pone el acento sobre la especificidad de la recepción del materialismo marxiano en los trabajos de Horkheimer y de Adorno, pues "comprendiendo el presente como una historia por configurar y protestando contra la injusticia, su comprensión de Marx resultó siempre selectiva. Es decir, no podrían estar presentes en ella, siempre y en la misma medida, todos los componentes de la doctrina heredada". A. SCHMIDT, Die Kritische Theorie als Geschichtsphilosophie (Hanser, München, 1976) 15.

44. H.-G. BACKHAUs, Theodor W. Adorno über Marx. Was bedeutet Kritik der politischen Ökonomie? Aus einer Seminarmitschrift im Sommersemester 1962, en Dialektik der 
El marxismo se presenta para la Teoría Crítica como un lugar privilegiado desde el que plantear desde una perspectiva distinta el problema de la praxis y de la emancipación, pues entienden que el objetivo de la teoría materialista es precisamente su propia disolución: "se trataría de alcanzar un estado en el que se eliminara el dominio ciego que ejercen las condiciones materiales sobre los hombres y en el que la pregunta por la libertad fuera un sinsentido" Adorno hace suyo el ideal de humanidad marxiano de un estado de reconciliación entre los individuos y sus relaciones, de ahí que el impulso materialista de su filosofía apunte a la "explosión de la cosificación" "46, esto es, a la abolición de los mecanismos que se ocultan en la sociedad moderna y que suponen el germen del dolor, pues no los entiende como fenómenos accidentales, sino como consecuencias derivadas de la estructura deformada del sistema capitalista $^{47}$. Pondrá el acento, además, en recuperar el verdadero motor del materialismo que encuentra, como se ha visto, en el análisis del principio de intercambio, entendido como el mecanismo de dominio social que tiende a la integración de lo particular ${ }^{48}$.

Con Marx, comprende el ser-natural de la sociedad capitalista como real y aparente al mismo tiempo; pues la legalidad natural de lo social es ideológica cuando se hipostasía, pero se torna real en cuanto ley que caracteriza el movimiento de una sociedad pseu-

Wertform. Untersuchungen zur marxschen Ökonomiekritik (Caira Verlag, Freiburg i.B., 1997). Véase, además, G. MARRAMAO, Zum Verbältnis von Politischer Ökonomie und Kritischer Theorie, "Ästhetik und Komunikation" 11 (1973) 79-93.

45. PhT, vol. II, op. cit., 198. En este sentido, Schmid Noerr ve en la filosofía de Adorno un intento de concreción de "el fin del materialismo conectado con la liberación filosófica y escatológica del dominio material sobre los hombres". G. SCHMID NOERR, Für einen kritischen Materialismus der Praxis, en M. Lutz BaCHMann, G. SCHMID NoERR (eds.), Kritischer Materialismus. Zur Diskussion eines Materialismus der Praxis (Hanser, München, 1991) 37.

46. Th. W. AdORnO, Musikpädagogische Musik. Brief an Ernst Krenek, en AGS, vol. 18, 810.

47. Cfr. B. Lindner, Herrschaft als Trauma. Adornos Gesellschaftstheorie zwischen Marx und Benjamin, en H. L. ARNOLD (ed.), Theodor W. Adorno (text+kritik, München, 1977).

48. Para un análisis de la relación entre generalidad y particularidad en la obra de Adorno, véase el interesante trabajo doctoral de M. Tichy, Theodor W. Adorno. Das Verbältnis von Allgemeinem und Besonderem in seiner Philosophie (Bouvier, Bonn, 1977). 
donatural en la que se da una integración cada vez mayor de sus miembros individuales: "cuanto más implacablemente se apodera la socialización de todos los momentos de la inmediatez humana e interhumana, tanto más imposible se hace recordar el ser devenido de la trama y tanto más irresistible es la apariencia de la naturaleza"49. La doble comprensión descriptiva y crítica de la idea marxiana de bistoria natural determina, en gran medida, el objetivo materialista de la filosofía de Adorno. Un objetivo que se entiende como el diagnóstico de la persistencia real del dominio y, al mismo tiempo, la demanda de su superación:

Éste es el giro decisivo de Marx. Que no dice simplemente, como cualquier socialista o anarquista primitivo que se oponen a la sociedad burguesa: todo esto no es verdad. Sino que, además, dice: queremos, para cambiar este importante aparato, ponerlo en movimiento por sus propias fuerzas (...) En lugar de reprochar simplemente a la sociedad burguesa su pretensión de realizar la armonía, la toma muy en serio y se pregunta: ¿es la sociedad que enseñáis verdaderamente idéntica a su concepto? ¿Corresponde a vuestro mundo de intercambio libre y justo, como vosotros afirmáis, una sociedad libre y justa? ${ }^{50}$

El momento crítico que observa en el pensamiento de Marx y en su descripción de la historia como historia natural o Naturgeschichte no sólo es la búsqueda de una utopía de lo social entendida como libertad frente al dominio de la praxis. Constituye además su intento de penetrar más allá de la apariencia de los fenómenos con el fin de mostrar su unidad como encubrimiento de una contradicción real. Cuando señala la prioridad de las condiciones materiales sobre la vida del individuo, muestra una actitud de crítica y de denuncia ante este determinismo, y el deseo de alcanzar una autonomía del sujeto basada en la liberación de las condiciones objetivas que pesan sobre él. Pues, como sostendrá Adorno años después, "su interés es supe-

49. $A G S$, vol. $6,351$.

50. PhT, vol. II, op. cit., 261. 
rar la forma de la historia como historia natural a favor del reino de la libertad" 51 . Esta realización de una auténtica sociedad racional e idéntica, es decir, de un intercambio justo, será el momento utópico de la filosofía marxiana que pretenderá hacer suyo.

La teoría materialista de Adorno se presenta como un diagnóstico crítico de los rastros de una sociedad endurecida que, a la vez, endurece las conciencias. Pero trata, además, de rescatar el impulso transformador que pervive en toda filosofía materialista y que emerge de la situación real que quiere denunciar: la determinación de la objetividad social como totalidad antagónica que ha olvidado su génesis y que se presenta bajo la forma de una "segunda naturaleza" inevitable. Aquí reside uno de los elementos específicos de su materialismo frente al de Marx, pues a diferencia de éste, Adorno no entiende la superación de la filosofía idealista en su integración en una teoría de lo social. Por el contrario, entiende la crítica al concepto como crítica social, y viceversa, sobre la base de una comprensión de la cosificación como el resultado de la hipóstasis de la inmediatez que se origina cuando se olvida la determinación natural del sujeto. Utopía no sólo significa el momento de protesta contra la lógica dominante que pesa sobre el individuo, sino que también incluye la indicación de los medios adecuados para su transformación. Se trata, pues, de abrir la posibilidad de una experimentación de la negatividad dentro de la positividad dominante. Esto se traduce en la búsqueda de nuevas vías para la teoría (y su lenguaje) y para la praxis que, bajo la forma de una "experiencia metafísica y negativa", asuman el carácter negativo de la cultura y, con ello, también su potencial emancipador.

51. Th. W. AdoRno, Zur Lebre von der Geschichte und der Freibeit. 1964-65 (Suhrkamp, Frankfurt a. M., 2001) 170. 